\title{
Am Seerosenteich
}

\author{
Christine Fiebig
}

Der wöchentliche Besuch am Seerosenteich im Palmengarten ist für Fotografin WITE VOLTMER Fiebig und Zeichnerin Christine Fiebig aus Frankfurt am Main ein einjähriges Kunstprojekt voller wunderschöner Motive. Zunächst warten wir auf die ersten Seerosenblätter an der Oberfläche des Beckens. Das Wasser spiegelt nur den Himmel, aber unter der Oberfläche sieht man schon die ersten Blätter aus dem schlammigen Grund emporwachsen.

Endlich sind sie da. Jetzt kann man ihnen beim Wachsen zusehen. Die Blätter lösen sich von der Wasseroberfläche, manche sind noch zusammengerollt; Wasser auf ihrer Oberfläche spiegelt den Himmel, unter den Blättern befinden sich Schatten, Spiegelbilder und die ersten Blütenknospen. Fische stehen zwischen den Blattstängeln. Dann öffnen sich die Blüten. Erst die weiße Nymphaea alba, dann die hellblaue, zarte Nymphaea x daubenyana sowie die rote Nymphaea rubra. Sie schweben über ihren Spiegelbildern, hell leuchtend auf dem schwarzen Wasser.

Die Eleganz der Linien, Formen und Farben am Seerosenteich und der besondere Reiz des Wassers, das Himmel, Pflanzen und das Leben auf dem Grund vereint, sind voll faszinierender Schönheit. Der Gärtner kommt und begutachtet seine Pflanzen im Wasser. Kinder- und Schülergruppen ziehen an uns vorüber. Teichhühner beobachten uns aus einiger Entfernung. Wir haben Zeit für einen kurzen Austausch mit anderen. Binsen, Wasser-Iris und Schwimmfarn bereichern unsere Motive, bis schließlich Mitte Juli die Blätter der Indischen Lotosblume sichtbar werden. Sie wachsen hoch, große Teller in mattem Grünblau, von der Sonne durchschienen; in der Mitte sind oft spiegelnde Wassertropfen zu sehen. Die kurzlebigen, prächtig rosa Blüten halten wir in allen Lebensstadien fest - bis zu den hölzern wirkenden Fruchtständen, die auf langen Stängeln über den Blättern stehen.

Im Herbst ist uns die vergehende Schönheit der Pflanzen am Seerosenteich ein reizvolles Motiv. Die Farben ändern sich allmählich von
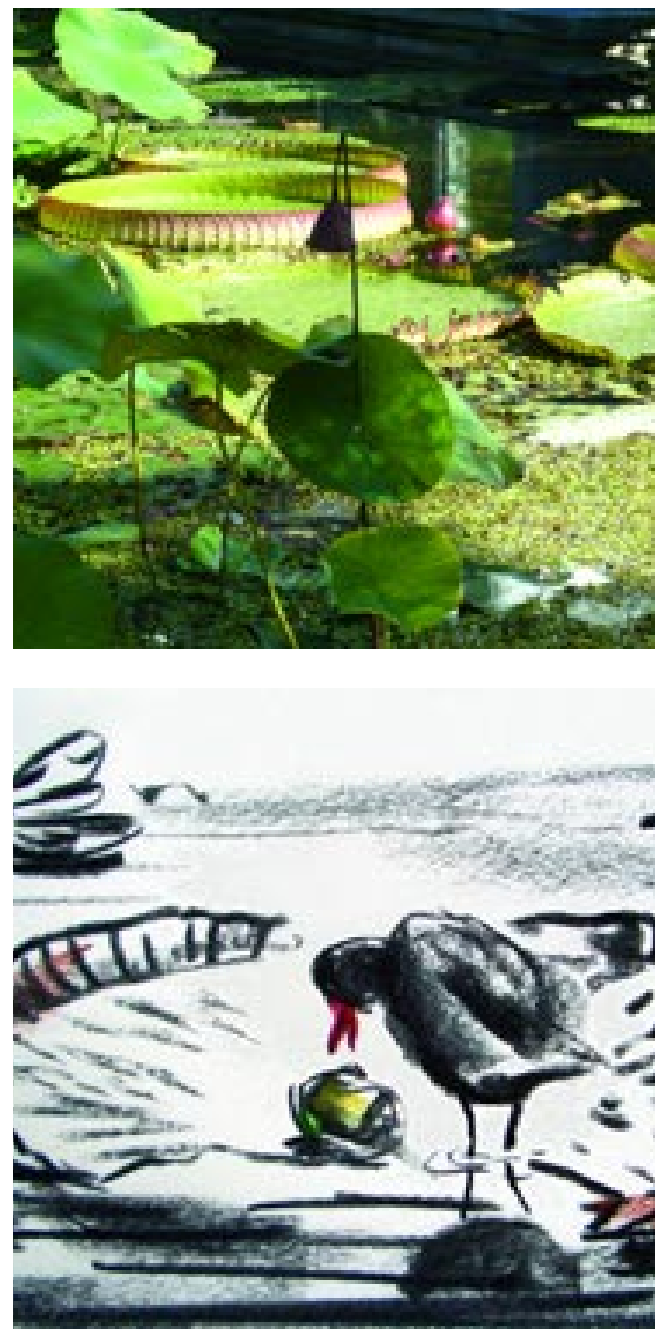

frischem Grün zu vielfältigen Brauntönen, die Pflanzen ziehen sich zurück und nehmen neue, interessante Formen an, bis das Eis schließlich die Wasseroberfläche überzieht.

Abb. 1 (oben): Victoria- und Lotosblumen-Blätter.

Abb. 2 (Mitte): Teichhuhn auf Victoria-Blatt. 

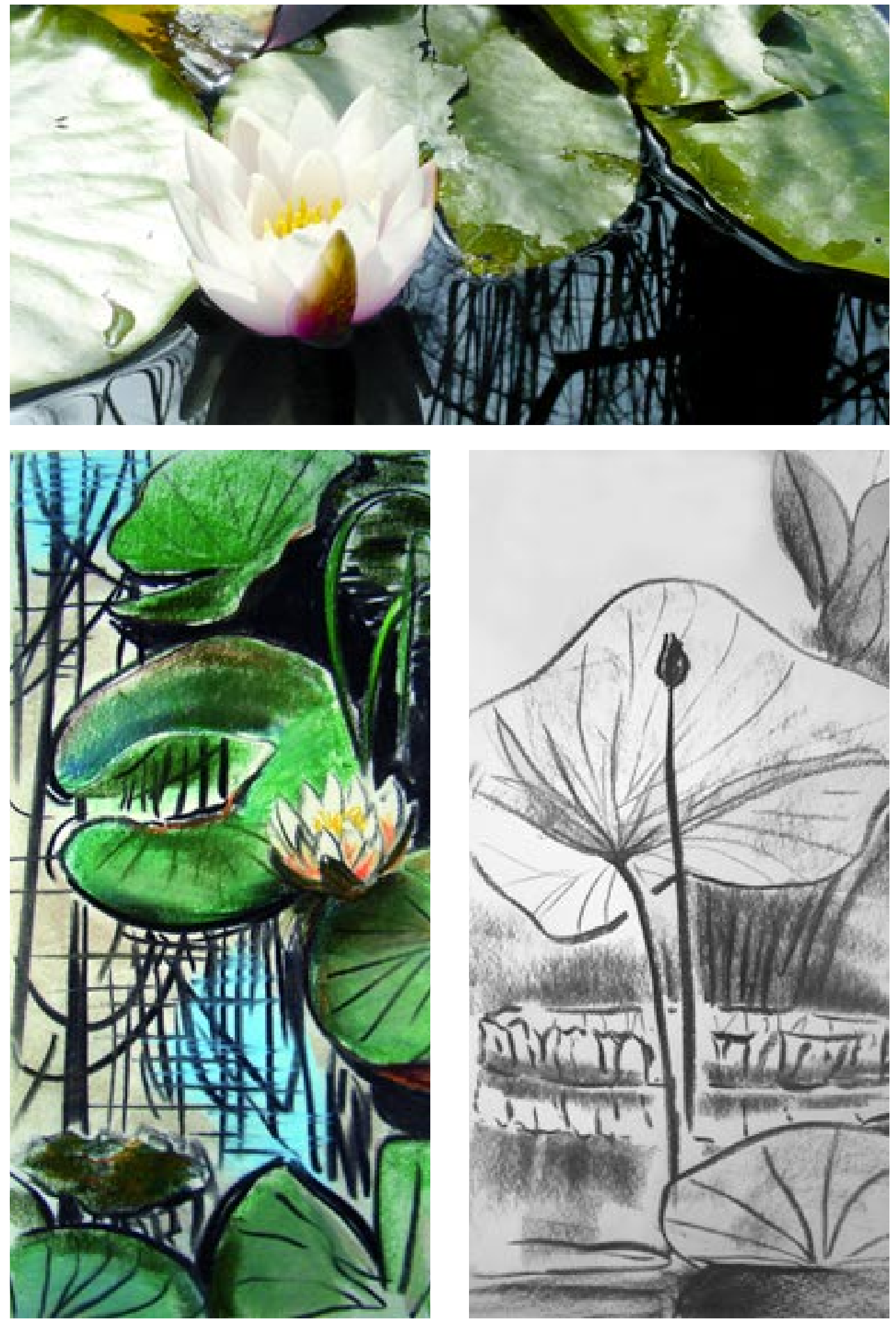

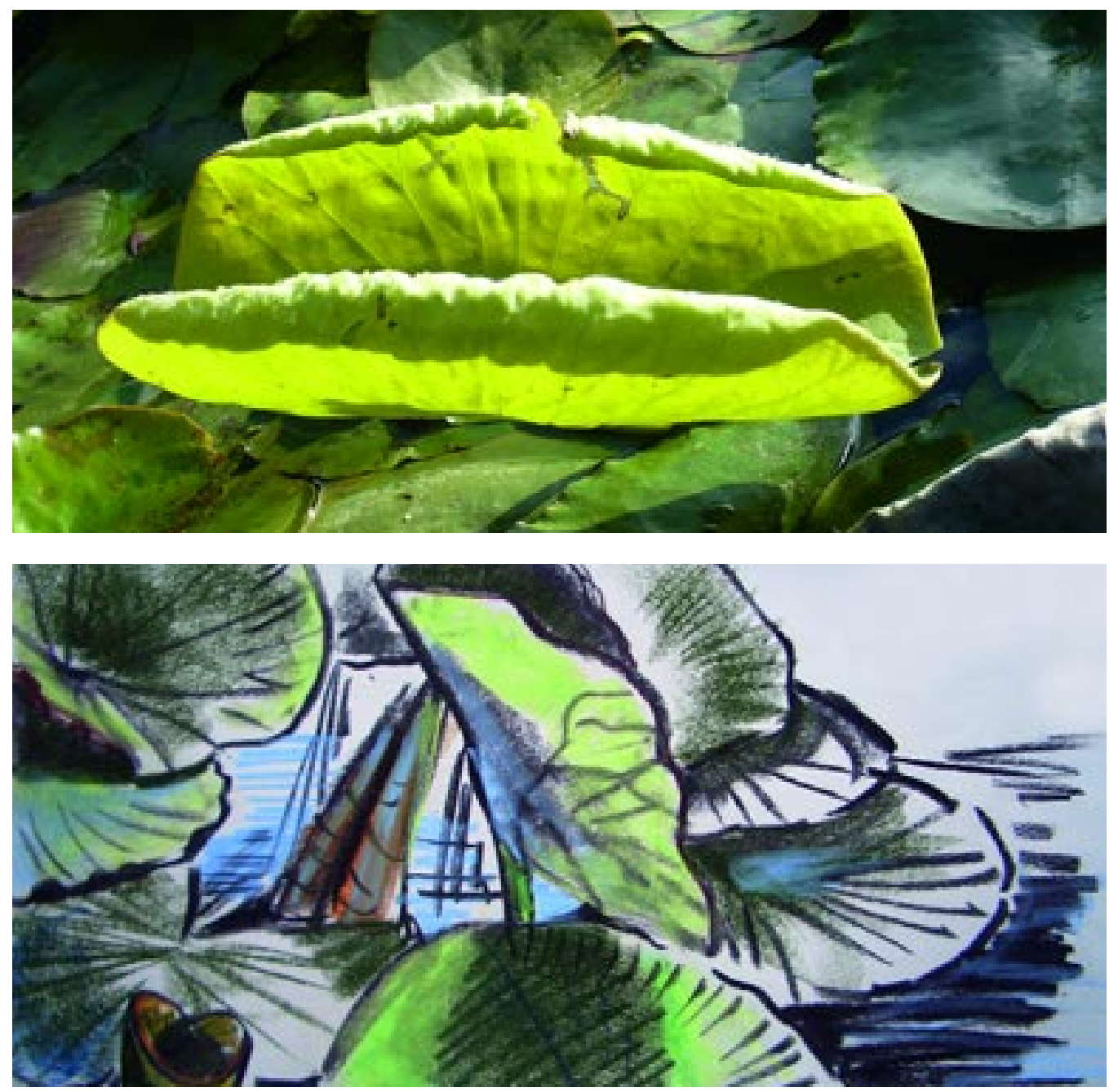

Abb. 3 (S. 56, oben): Weißblütige tropische Seerose.

Abb. 4 (S. 56, links): Wasser, Licht, Schatten und Seerosen.

Abb. 5 (S. 56, rechts): Lotosblume in Schwarz-Weiß.

Abb. 6 (S. 57, oben): Junges Lotosblumen-Blatt.

Abb. 7 (S. 57, Mitte): Lotosblumen- und Seerosenblätter.

Abb. 8 (S. 57, unten): Vergänglichkeit einer Seerosen-Blüte.

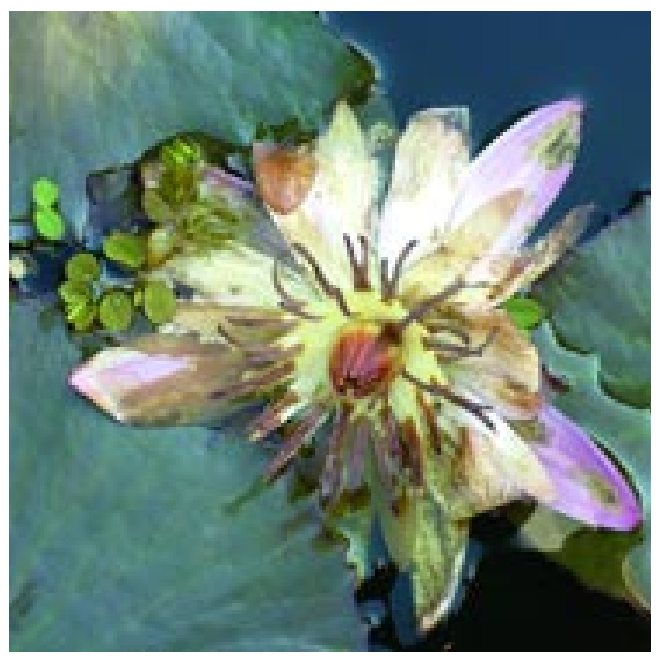

